\title{
Fire alert system through text messages, with arduino mega technology and GSM SIM 900 module
}

\author{
Omar Chamorro-Atalaya, Dora Arce-Santillan \\ Facultad de Ingeniería y Gestión (FIG), Universidad Tecnológica de Lima Sur (UNTELS), Perú
}

\begin{tabular}{l}
\hline \hline Article Info \\
\hline Article history: \\
Received Sep 1, 2019 \\
Revised Dec 3, 2019 \\
Accepted Dec 17, 2019 \\
\hline
\end{tabular}

\section{Keywords:}

Alert system

Concentration level

Distance

Fire

Gsm module

Reception time

Sensor

Text messages

\begin{abstract}
The purpose of this article is to develop a fire alert system, to implement under the use of Arduino Mega technology and GSM module SIM 900 (GSM: Global System for mobile communications, SIM: Minimum System), with which through The programming and interconnection between these components can be obtained by capturing data through MQ2 sensors installed in the Industrial Automation Laboratory of the National Technological University of South Lima, and then send a fire alert signal through text messages to a mobile equipment located outside the laboratory; at a distance of 1000 meters; The relevance of this research is that its optimal response, detects the application of this system to the industrial park of Villa El Salvador, which has multiple warehouses, which a newspaper is affected by fire hazards, by the amount of flammable material They owned. Developing the investigation will determine the existence of a correlation factor of 0.973 , between the reception time of the alert signal, with respect to the distance in the MQ2 sensor to detect the smoke; This factor tells us to state that the correlation is significant between both variables; with a ratio percentage equal to $98.90 \%$, which was selected by the determination factor $R^{2}$.
\end{abstract}

Copyright $(2020$ Institute of Advanced Engineering and Science. All rights reserved.

\section{Corresponding Author:}

Omar Freddy Chamorro Atalaya, Facultad de Ingeniería y Gestión (FIG), Universidad Tecnológica de Lima Sur (UNTELS), Perú.

Email: omar_chamorro1@ @otmail.com

\section{INTRODUCTION}

It is essential that every company has safety and health measures for its workers, especially if in the work being carried out toxic substances, high voltages are manipulated or there is any risk of an accident, such as a fire [1]. It is necessary to have the preventive measures, so that a fire event does not occur, and for this a solution is to detect it before it is too late and avoid major misfortunes [2].

In recent years, technology has advanced exponentially. Today we are accustomed to living dependent on mobile, computer or a Tablet. But these technological comforts have emerged in the last 10 years [3]. The same is happening although in a less pronounced way in homes, buildings or even in cities [4]. It is already common to find homes with surveillance connected to computers or other devices in the home, have alarm systems for housing control [5].

Computational science is a branch that has undergone major transformations, which presents an improvement in the technology of our environment [6]. Technically the houses of today were considered as intelligent in the seventies, an example of this is the application of motion sensors that control the lighting [7]. The ability to link motion sensors for a security alarm or intruder detection are commonly employed in facilities [8].

Often, minimal carelessness in homes, warehouses or stores can cause serious consequences and can be the cause of some inputs contained in such environments, such as solvents, paint or alcohol, become inflamed. Without preventive measures, these spaces would catch fire completely in a short time [9]. 
As a consequence, people would be endangered, the environment would be harmed in the long term, the activity of the company would be interrupted and repairs and sanitation would be necessary that would entail high costs [10].

In January 2016, the news of the fire in one of the stores of a well-known supermarket surprises Lima where, regardless of the causes of the incident, a call to reflect on whether Are our stores really safe?, and if despite complying with the basic standards suggested by the National Security and Civil Defense Regulations ¿Can we do something else to avoid an accident? [11]. The low-cost fire detectors available in the market are very limited with smoke detection features and sound alerts without offering greater benefits to the user [12]. The lack of a reliable and stable system that can monitor, control and alert on an incident can cause invaluable losses, ranging from material losses, to human losses [13].

Hence the idea of improving the treatment of this problem by implementing low cost and reliable technologies with the objective of saving the storage of material and human goods [14]. The use of programmable plates grows every day to provide infinite possibilities of operation, which makes possible the development of molded systems with functionalities that are deemed essential, at reasonable cost and with the possibility that said system is scalable, fully dynamic with the user and with online management [15]. The expansion of mobile phone networks throughout the national territory has opened the door to an efficient and low-cost alternative for monitoring and control of equipment located in remote locations [16]. To monitor variables in remote and hard-to-reach places, we can use the cellular telephone network as a communication channel, accessing it through GSM technology and using the appropriate equipment to make such a connection [17].

\section{PROCEDURE}

The results were obtained from the implementation of a fire alert system, whose data capture was carried out through two MQ2 sensors, distributed in the Industrial Automation laboratory of the Technological University of Lima Sur; whereby the captured data was sent to the Arduino Mega Card, which was responsible for processing the data, to send it to the SIM card 900; the same one that will be in charge through the GSM technology send to a mobile equipment, located outside the laboratory; the same one that moved within a radius of 1000 meters; This distance is referential, and was taken for the purpose of determining an initial point of analysis.

Figure 1 shows the representation of the connection architecture of the components or modules that will allow the capture, processing and sending of the alert signal by text message to a mobile device. The SIM 900 module, shown in Figure 1, operates under the GSM/GPRS quad-band technologies, works at frequencies GSM 850MHz, GSM 900MHz, DCS 1800MHz y PCS 1900MHz. The SIM 900 module has 4 pins two of GND (Ground) and VCC (DC voltage), which operates at 3.7V and two pins Tx (Transmission) and Rx (Reception). The Tx is connected to pin 10 and the Rx is connected to pin 11 of the Arduino Mega module, which will allow transmission with a maximum transmission rate of $85.6 \mathrm{Kbps}$.

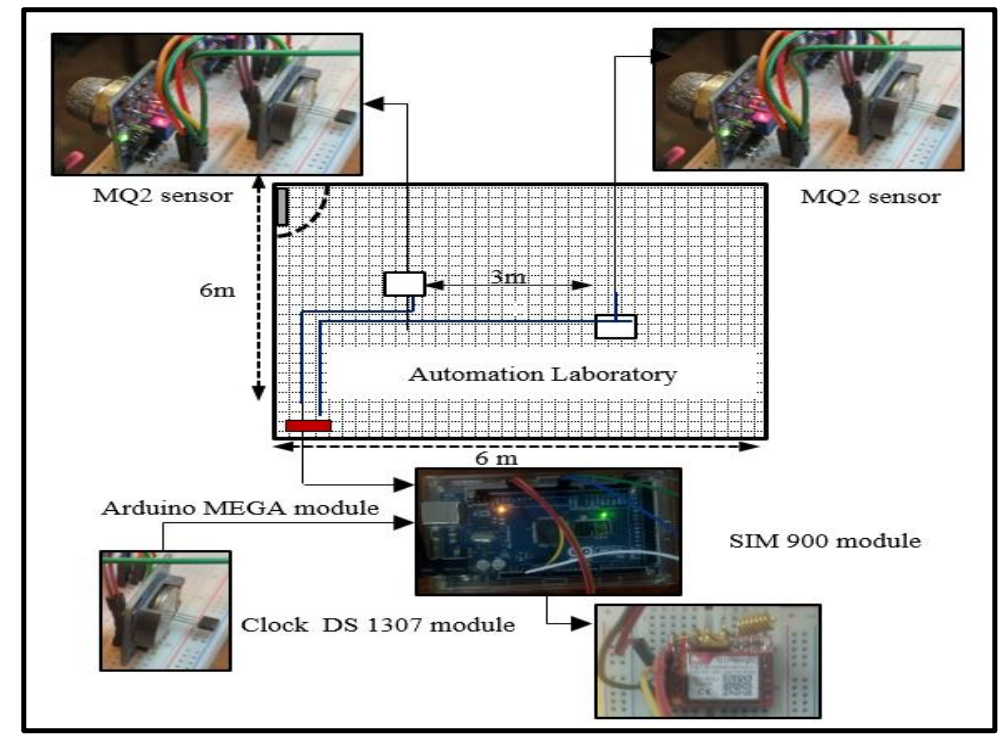

Figure 1. Fire Alert System Architecture 
The Smoke sensor MQ2 work with 3 pins; the first is VDC Voltage, which is powered by 5 volts; the second is the GND (Ground) and the third is where it sends the analog signal. The sensor operates as follows, as soon as the sensor picks up smoke, its voltage level increases in proportion to the level of smoke it detects. Additionally, with the purpose that in the text message sent by the SIM 900 module, the mobile device records which sensor was the one that detected the gas or smoke and also specifies the time at which the detection was carried out, is that a DS 1307 Clock module.

This module works with 4 VDC 5 volt, GND and two SDA and SCL pins that fit the use of an I2C library, which allows us to connect and receive moments or pulses constantly. That is why the clock module is coupled with the Arduino Mega, in order to work your clock correctly. The Arduino Mega module has pins SDA and SCL on pins 20 and 21 respectively. The connection is made directly the pins are not inverted. Next in Figure 2, the programming of the Arduino Mega module is shown.

The previous figure shows the use of Wire and RTC libraries, it is with the purpose of attaching the Arduino Mega module, the Clock module, so that the warning signal that is generated is via text messages specify the day and time in which the presence of smoke is detected. Additionally, the serial software library is used to enable analog output pins, such as receiving and sending data pins. In this case the SIM 900 has two TX and RX pins connected to pin 10 and 11 of the Arduino Mega module, respectively. In Figure 3, the second segment of the Arduino Mega programming is shown.

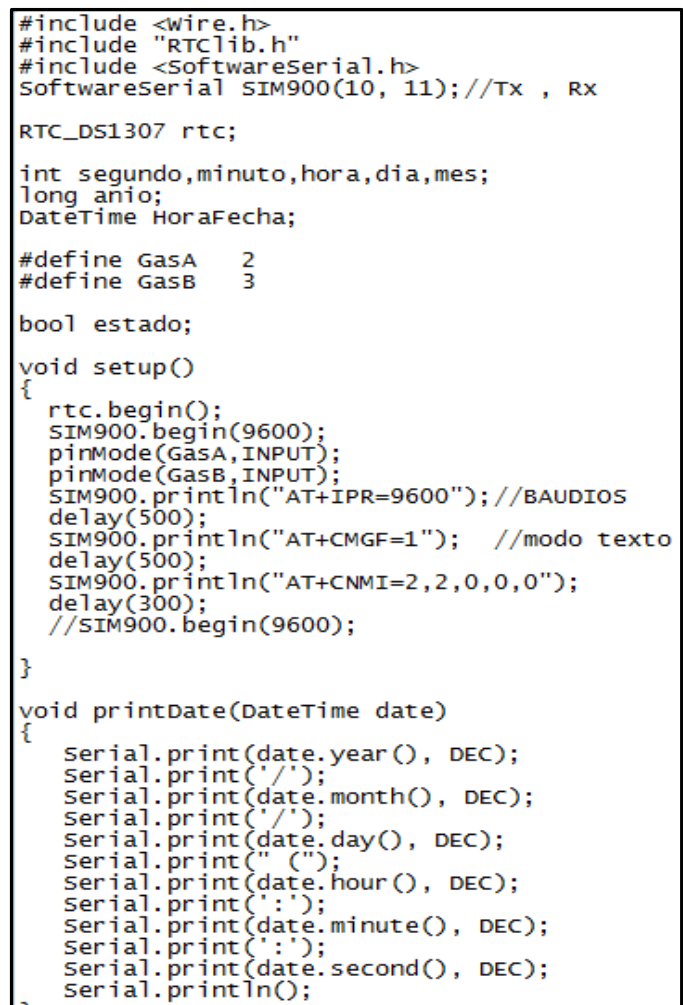

Figure 2. First segment of the arduino mega programming

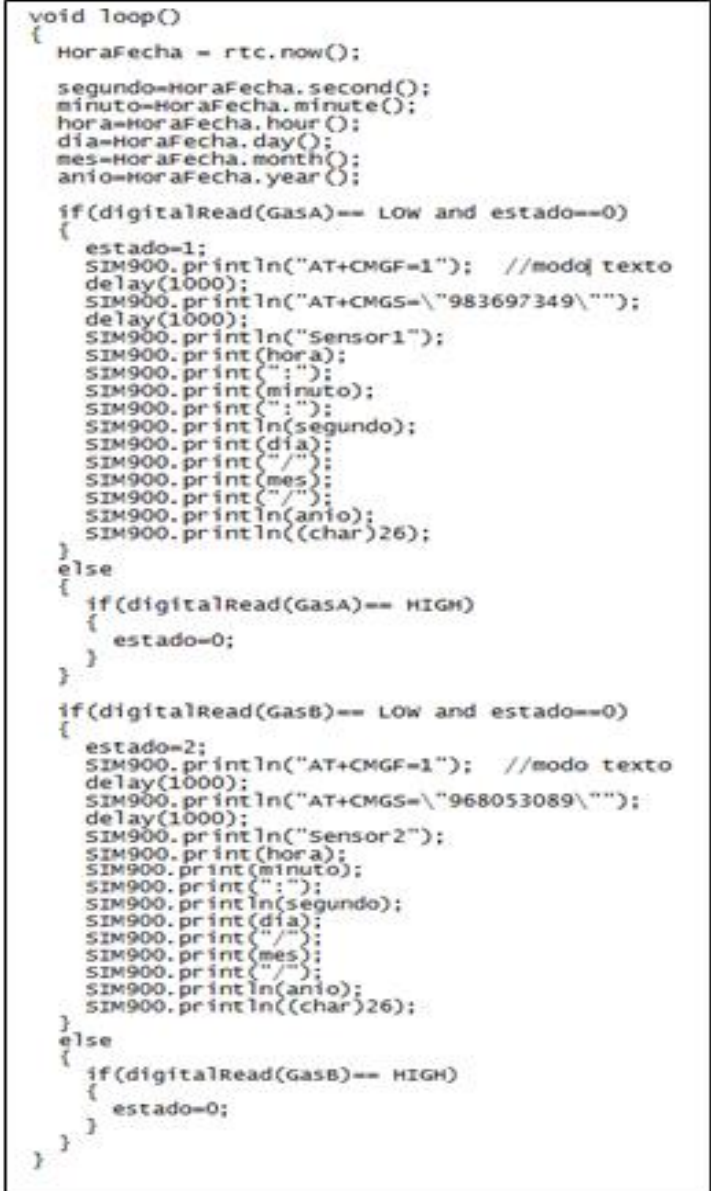

Figure 3. Second segment of the arduino mega programming

The RTC library is defined in the previous figure, which is an extensive family of clock modules that we will use in our project. In this case it is the DS-1307 module. Then we define variables in which we will save data in this case we implement hour, minute, second, day, month. We have a Long variable of name anio since the Arduino source code does not accept the letter $\tilde{n}$. and a Long type variable, since it will store much more memory.

\footnotetext{
Fire alert system through text messages, with arduino mega technology and... (Omar Chamorro-Atalaya)
} 


\section{RESEARCH METHOD}

\subsection{Research Level}

The research carried out is of a descriptive level, since it is based on using the properties of the Arduino Mega technology and the SIM 900 module, so that through a synergy between them, it is possible to generate warning signals from the detection of smoke, using MQ2 sensors (gas or smoke sensor). This will describe the results obtained in relation to the detection distance of the sensor and the time it takes for the signal to be received on a mobile device, through text messages [18].

Thus, it is also correlational, since it aims to discover the level of association between the time it takes for the signal to be received in a mobile device, with respect to the distance at which the MQ2 sensor detects gas or smoke; this through discovering the dispersion model and its determining factor [19].

\subsection{Population and Sample}

The unit of analysis, that is to say the main entity that is being analyzed in the research, is the Industrial Automation Laboratory of the National University of South Lima, on which the MQ2 sensors were installed; that due to its dimensioning (36 m2), two sensors were used [20].

\subsection{Data Collection}

The data collection will be carried out through technical reports, in which it is intended to make the data captures, in a time interval of two minutes; the data associated with the investigation are the distance which the sensor detects the smoke and the time in which the signal reaches the cellular equipment [21]

\section{RESULTS AND DISCUSSION}

\subsection{Results}

The data was obtained experimentally from smoke exposure, only to one of the MQ2 sensors; since, if we consider that both sensors have the same characteristics, it was determined to carry out the tests in one of them. From the previous table it can be specified that the correlation factor is 0.973 , which indicates that there is a high level of association between the variables under analysis. Evidence of sending and receiving text messages as shown in Figure 4.

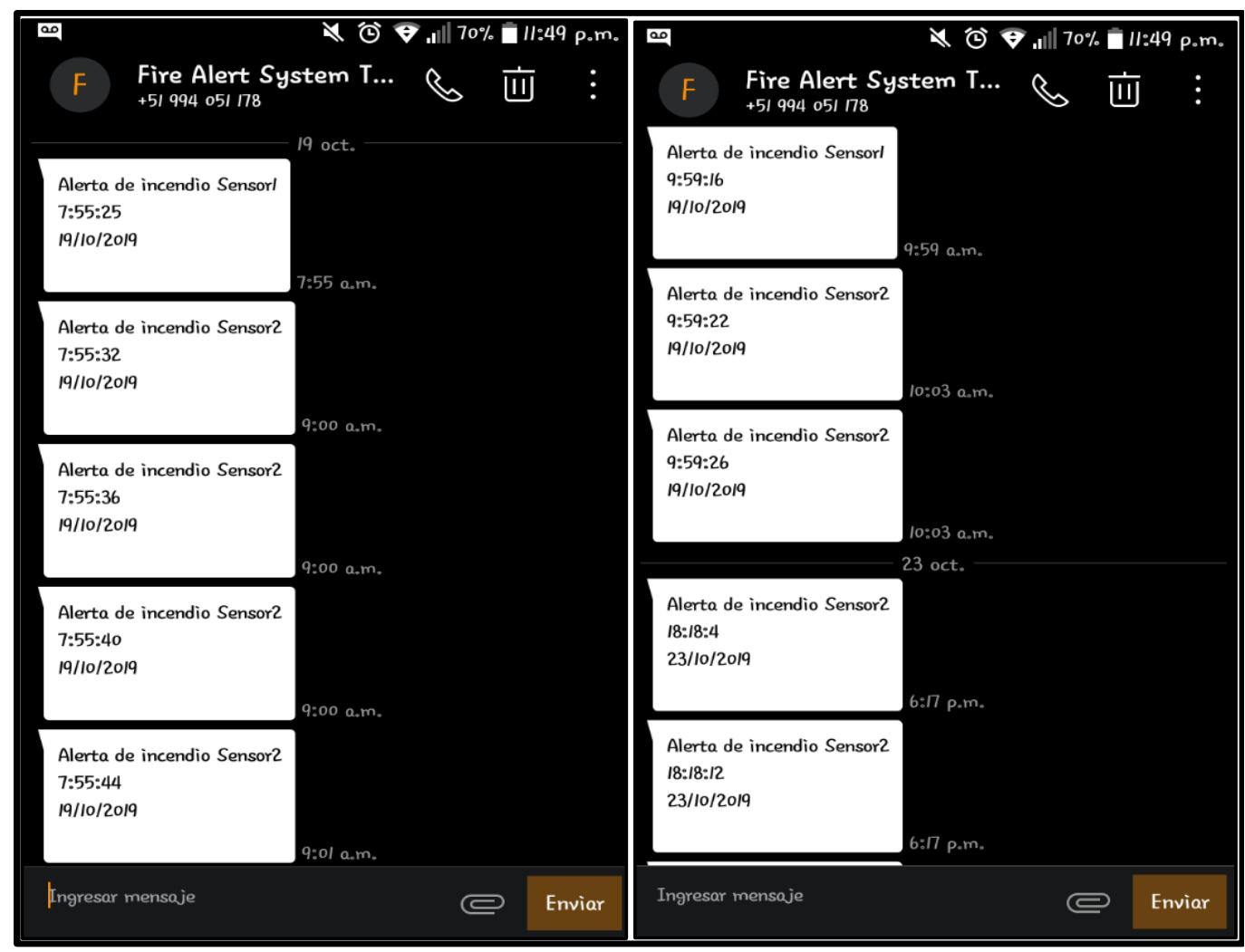

Figure 4. Evidence of sending and receiving text messages 
With the data collected, the correlation factor was determined, and then some data from a dispersion analysis, thus establishing the model and determining factor that describes the behavior of the reception time of the alert signal, with respect to the distance in which the MQ2 sensor detects gas or smoke. It should be noted that I apply the Pearson correlation because there is no normal distribution in the data.

From the previous Table 1, it can be specified that the correlation factor is 0.973 , which indicates that there is a high level of association between the variables under analysis. Figure 5 as shown dispersion model of the collected data. From the previous figure, it is shown that the model that best represents the behavior of the collected data is the quadratic one; Also in the following Table 2 the coefficient of determination R2 is determined, which is 0.989 . That is, the relationship between the variables is $98.90 \%$.

Table 1. Pearson Correlation Analysis Result

\begin{tabular}{|c|c|c|c|}
\hline & & $\begin{array}{l}\text { Distance from the smoke source to } \\
\text { the MQ2 sensor }\end{array}$ & $\begin{array}{l}\text { Time to receive the text message } \\
\text { on the cell phone }\end{array}$ \\
\hline \multirow{3}{*}{$\begin{array}{l}\text { Distance from the smoke source } \\
\text { to the MQ2 sensor }\end{array}$} & Pearson Correlation & 1 & $0.973^{* * *}$ \\
\hline & Sig. (bilateral) & & 0.000 \\
\hline & $\mathrm{N}$ & 11 & 11 \\
\hline \multirow{3}{*}{$\begin{array}{l}\text { Time to receive the text message } \\
\text { on the cell phone }\end{array}$} & Pearson Correlation & $0.973^{* *}$ & 1 \\
\hline & Sig. (bilateral) & 0.000 & \\
\hline & $\mathrm{N}$ & 11 & 11 \\
\hline
\end{tabular}

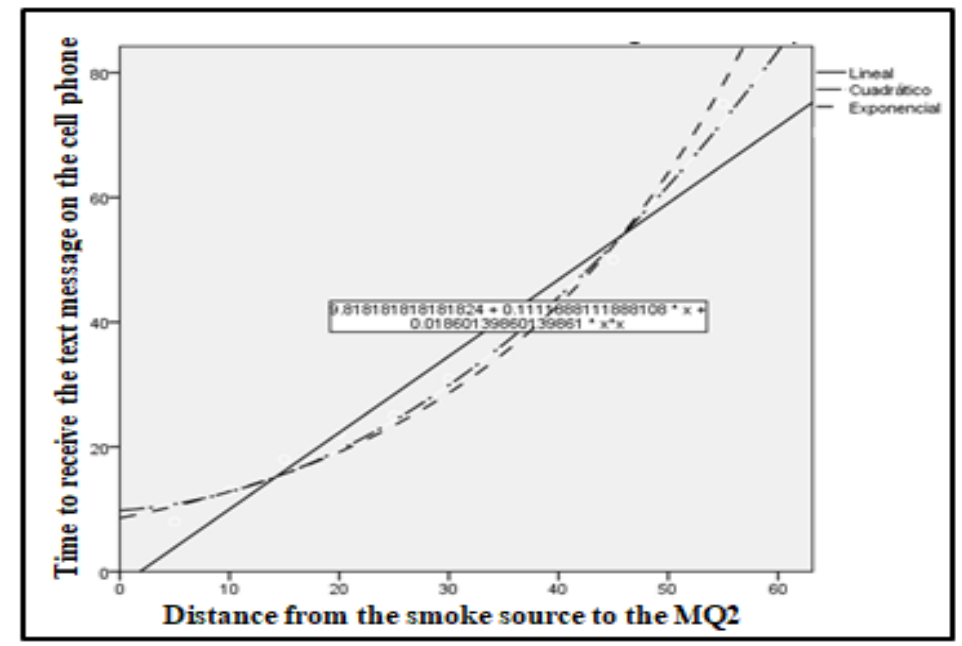

Figure 5. Dispersion model of the collected data

Table 2. Result of the R2 of other Dispersion Models Analyzed

\begin{tabular}{ccc}
\hline \multirow{2}{*}{ Equation } & Model Summary & \\
& $\mathrm{R}^{2}$ & SIG. \\
\hline Linear & 0.947 & 0.000 \\
Quadratic & 0.989 & 0.000 \\
Exponential & 0.972 & 0.000 \\
\hline
\end{tabular}

\subsection{Discussions}

In relation to the results obtained experimentally, and having performed the correlation analysis and dispersion model of the data obtained as part of the research; The following discussions are detailed:

In reference to the fire alert system by means of text messages, implemented with Arduino Mega technology and GSM SIM 900 Module, the system was able to send text messages optimally, thus achieving both the sensors, the programming of the Arduino Mega and the GSM SIM900 module, respond efficiently as required. In this regard, in the research carried out at the Technological University of Peru, they indicate that: the correct installation of the data acquisition devices was achieved using the Arduino block, which allowed the correct communication between the sensor and the mobile equipment; in addition to overcoming the difficulties that arose, in addition an efficient programming logic was obtained that allowed

Fire alert system through text messages, with arduino mega technology and... (Omar Chamorro-Atalaya) 
the joint integration between the devices and the GSM SIM 900 module. To achieve this, the organization of the programming was prioritized and the general conditions were determined, reaching proper functioning of the tasks assigned to the system [22]. In both cases it is evidenced that from the correct synergy between the components involved in the fire detection system, the sending of the alert signal is achieved through text messages.

In reference to the data obtained in terms of time, it will take time to get the fire alert message to the mobile team we can establish that, there is a quadratic type relationship, with respect to the distance in which the source that generates the gas or smoke; that is to say, at a greater distance, the time in reaching the text message to the receiving equipment will be longer; In addition, it was evidenced in the experimental analysis that, the maximum distance at which the sensor detects the concentration of gas or smoke is $75 \mathrm{~cm}$, above this distance, no alert message is generated. In this regard, in the research carried out at the Technical University of the North, it is pointed out that, with the performance of these tests, it can be concluded that a fire alarm signal was sent through the GSM 900 Module, provided that The fire is close to the MQ2 sensor, approximately 1 meter, evidencing that the greater the distance the greater the time it will take to get the signal to the receiving equipment [23]. In part I agree with the author of the aforementioned text, since on the one hand it establishes that the greater the distance from the gas source to the sensor, the longer the signal takes to reach the receiving element; however, in terms of the maximum distance in my investigation it was $75 \mathrm{~cm}$, while in its case it was 1 meter, it is possible that this difference lies in the concentration of the gas in the environment that was used for the tests, in my case it was $1045 \mathrm{ppm}$ while in its case it was $1450 \mathrm{ppm}$.

\section{CONCLUSION}

It is concluded that he managed to send text messages as part of the fire alert system implemented with Arduino Mega technology and GSM SIM 900 Module, managing to determine that there is a correlation factor of 0.973 , between the reception time of the alert signal, with respect to the distance in which the MQ2 sensor detects gas or smoke; This factor allows us to state that the correlation is significant. In addition, it is concluded that the model that determines the behavior of the reception time of the alert signal by a mobile device, with respect to the distance in which the MQ2 sensor detects gas or smoke, is quadratic, with a determining factor R2 is 0.989. Finally, it is concluded that the fire alert system implemented with Arduino Mega technology and GSM SIM 900 Module allows text messages to be sent, responding optimally to signals between 0 and $70 \mathrm{~cm}$, for a concentration level of $1045 \mathrm{ppm}$; if the gas or smoke signal is above this distance the alert signal is not generated.

\section{ACKNOWLEDGEMENTS}

The authors wish to recognize and thank the National Technological University of South Lima for their support of this investigation.

\section{REFERENCES}

[1] L. Chávez, "Electronic Early Warning System for Fire Detection in the ACETERM Company of the city of Santo Domingo de los Tsáchilas", M.S.thesis, Technical University of Ambato, Ambato, Santo Domingo, 2017.

[2] J. Ortiz, "Benchmark sensor selection for a WSN vision of Data Collection for an Early Forest Fire Alert system", M.S.thesis, North Technical University, Ibarra, Ecuador, 2017.

[3] N. Martínez, "Low consumption Monitoring System with electronic ink display and Internet connection", M.S.thesis, Jaen University, Jaen, Colombia, 2018.

[4] J. Alvarado, "Operating Monitoring System with GSM/GPRS technology and energy saving for Frozen product containers", M.S.thesis, University of Piura, Piura, Perú, 2016.

[5] A. Rodríguez, "Design of a centralized home automation system", M.S.thesis, Universidad de Valladolid, Valladolid, España 2016.

[6] G. Larrea, "Design and description of an automated fire system on a yacht 45 meters long", M.S.thesis, Santiago de Guayaquil Catholic University, Guayaquil, Ecuador, 2016.

[7] M. Cano, M. Armenta, E. Cabal, and H. Juárez, "Design and simulation of a Smart Home control system", Higher Technological Institute of Irapuato, Mexico, Journal of Scientific and Technical Application, 13-19, 2016.

[8] E. Cabrera and A. Alomá, "Oil industry fire extinguishing system design. Part 3. Detailed pipe network model", Universidad Laica Eloy Alfaro de Manabí ULEAM, Ecuador, Journal Hydraulic and Environmental Engineering, pp. 33-47, 2015.

[9] F. Marco, "Design and implementation of a gas measurement system with Arduino", M.S.thesis, Zaragoza's University, Zaragoza,Spain, 2016.

[10] J. Gallardo, "Design and implementation of a self-sustaining telemetric prototype for monitoring Hydraulic conditions", M.S.thesis, Salesian Polytechnic University Headquarters, Guayaquil, Ecuador, 2016. 
[11] M. Narva. "Warehouse Security: Fire Systems", Company Fitflow Perú, Perú, Press room, 20-22, 2016.

[12] D. Villegas and R. Roa, "Prototype of a remote home security system", M.S.thesis, University of San Buenaventura, San Buenaventura, Colombia, 2017.

[13] D. Pareja, M. Mallorquín, A. Katia, and J. Arrúa, "Design of a prototype monitoring and control system for fire detection", University of Ciudad del Este, Uruguay, COMTEL 2016, VIII International Computer and Telecommunications Congress, pp. 280-286, 2016.

[14] J. Erazo and C. Hervas, "Forest fire detection system through sensory networks", University of Cuenca, Ecuador, Journal MASKANA, I+D+ingeniería, 1-11, 2016.

[15] F. Millán, "Design and implementation of a gas measurement system with Arduino", M.S.thesis, Zaragoza's University, Spain, 2016.

[16] N. Martínez, "Alarm, Transmission and Data Monitoring System applied". M.S.thesis, Catholic University of Manizales, Manizales, Colombia, 2016.

[17] A. Hernández, M. Ramos, B. Placencia, and B. Indacochea, "Cientific investigation methodology", Alicante: Ed. Innovation and Development Area, 2018.

[18] F. Arias, "The research project", sixth edition Mexico D.F: Episteme, 2016.

[19] R. Hernández, "Research Methodology”, tenth edition, Mexico D.F: Mc Graw Hill, 2019.

[20] C. Bernal, "Investigation Methodology", Fourth edition, Bogota: Editorial, 2016.

[21] C. Monge, "Qualitative and Quantitative Research Methodology", M.S.thesis, Surcolombia University, Colombia, 2016

[22] H. Mendez and J. Campos, "Prototype development of a Security system based on GSM technology for the Castro and Baca Family Company S.A.C.”, M.S.thesis, Technological University of Peru, Perú, 2016.

[23] J. Romero, "Fire Control and Protection System for the General Hospital of Macas in the province of Morona Santiago", M.S.thesis, Technical University of Ambato, Ambato, Ecuador, 2017.

\section{BIOGRAPHIES OF AUTHORS}

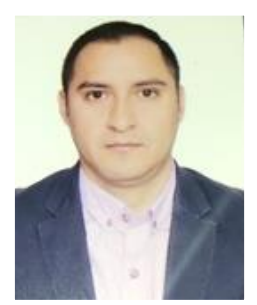

Omar Freddy Chamorro Atalaya is Electronic engineer, school and enabled with master's degree in systems engineering, with more than 15 years of continuous experience in the university chair, in public and private university. Master teacher in the industrial automation course. Professional experience in industrial network automation projects in drinking water systems. Author of several scientific articles in journals indexed in Scopus, in different areas, such as: Supervision and Process Control, Industrial Automation, Solar Panels, Automation of Fire Systems, implementation of Base Stations of Communications 4G-LTE and Behavioral Sciences.

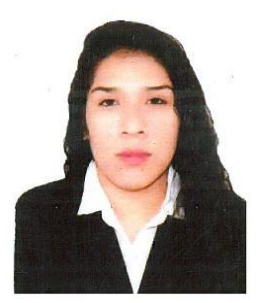

Dora Yvonne Arce Santillan is graduated electrician mechanical engineer at the Universidad Nacional de Lima Sur, colleged and enabled. With studies of Master in Electrical Engineering with mention in Project Management. Author of several scientific articles in journals indexed in Scopus, in different areas, such as: Supervision and Process Control, Industrial Automation, Solar Panels, Automation of Fire Systems and Behavioral Sciences. 